\title{
Reconstructing Pre-Industrial Long-Distance Roads in a Hilly Region in Germany, Based on Historical and Archaeological Data
}

\author{
IRMELA HERZOG \\ The Rhineland Commission for Archaeological Monuments and Sites, Germany
}

\begin{abstract}
The aim of this contribution is on the one hand to map pre-industrial long distance roads located in a hilly region east of Cologne, Germany as exactly as possible and on the other hand to assess the accuracy of least-cost approaches that are increasingly applied by archaeologists for prehistoric road reconstruction. Probably the earliest map covering the study area east of Cologne dates back to 1575. The map is distorted so that rectification is difficult. But it is possible to assess the local accuracy of the map and to transfer the approximate routes to a modern map manually. Most of the area covered by the 1575 map is also depicted on a set of more accurate maps created in the early 19th century and a somewhat later historical map set (ca. $1842 \mathrm{AD}$ ). The historical roads on these rectified historical maps close to the approximate roads were digitized and compared to the outcomes of least-cost analysis, specifically least-cost paths and accessibility maps. Based on these route reconstructions with limited accuracy, Lidar data is checked to identify remains of these roads. Several approaches for visualizing Lidar data are tested to identify appropriate methods for detecting sunken roads. Possible sunken roads detected on the Lidar images were validated by checking cross sections in the digital elevation model and in the field.
\end{abstract}

Key words:

Historical maps, Lidar data, least-cost analysis.

SDH Reference:

Irmela Herzog. 2017. Reconstructing Pre-Industrial Long Distance Roads in a Hilly Region in

Germany, Based on Historical and Archaeological Data. SDH, 1, 2, 642-660.

D0I: $10.14434 /$ sdh.v1i2.23283

\section{INTRODUCTION}

The aim of this study is to analyze the potential and limits of the combination of two approaches that are frequently applied in archaeological research to reconstruct the exact location of old routes: leastcost analysis and detection of archaeological sites using high resolution digital elevation models, derived from airborne laser scanning missions data (Lidar data, also known as ALS data). The test case consists of the roads depicted on a historical map created in 1575. This map covers about $500 \mathrm{~km}^{2}$ in a hilly rural region east of Cologne, Germany (Figs. la and 1b). For the last decade, both

Author's address: I. Herzog, LVR-Amt für Bodendenkmalpflege im Rheinland, Endenicher Str. 133, 53115 Bonn, Germany; email: i.herzog@lvr.de

Permission to make digital or hardcopies of part or all of this work is granted without fee according to the open access policy of SDH.

(c) 2017 SDH Open Access Journal 
least-cost analysis and the applications of Lidar data have become increasingly popular, resulting in a multitude of archaeological case studies.

Due to distortions and several other reasons, only the approximate modern location of the roads depicted on the map created in 1575 could be reconstructed. The initial hypothesis of this study expected that least-cost paths (LCPs) close to the approximate old roads indicate the location of these routes more precisely. Moreover, sunken roads with similar direction and close to the approximate old roads should indicate the exact location of the historical roads. Therefore, the areas close to the approximate old roads were inspected in visualizations of the Lidar data, and possible sunken roads were digitized.

The issues of transferring the roads depicted on the map created in 1575 to a modern map are discussed in the next section. The section also introduces several later historical map sets that provide additional information on the location of the features depicted on the map created in 1575. Transferring or digitizing selected old roads from these maps results in route bundles that allow assessing the local accuracy of these road reconstructions.

The subsequent section presents LCPs generated by applying three slightly different cost models. The LCPs connect pairs of settlement locations that are close to the approximate historical routes. Most of these settlements were already recorded in historical sources dated before 1510 AD. Moreover, an accessibility map based on one of the cost models shows possible corridors for the historical routes.

Another section investigates adequate methods for visualizing and detecting sunken roads in Lidar data for some test cases in the study region. The most appropriate methods are applied for the high resolution digital elevation data covering the study area. The section also discusses the issues of identifying sunken roads in Lidar data and methods for validation. A map of the possible sunken road sections close to the approximate historical routes is presented.

Finally, the limits and potential of both the least-cost and the Lidar analysis for precisely identifying the exact location of the historical roads are discussed, as well as outlines for future research.

\section{APPROXIMATE DIGITALIZATION OF THE ROADS ON HISTORICAL MAPS}

In 1575, the eldest son of the famous cartographer Gerhard Mercator created a map that was part of the evidence presented at one of the highest judicial institutions of that time. The map was commissioned by the rulers of the Berg territory in the course of the dispute with the rulers of Homberg concerning the boundaries of these territories [Mercator 1575]. This map, consisting of twelve sheets, is still preserved but in a fairly bad state. A reconstructed version of the map based on the original map and some later copies was published in 1995. The approximate scale of Mercator's map is about 1:25,000 covering about $500 \mathrm{~km}^{2}$ of a hilly region east of Cologne, Germany (Figs. la and 1b). The study area considered here is somewhat smaller because of data availability; previous research relied on a list of place names and the year when these sites were first mentioned [Pampus 1998]. Nearly all of the place names could be located on maps created in the late 19th century, and this allowed geo-referencing the centers of the settlements [Herzog 2015]. The study area is the intersection of the areas covered by Pampus and by Mercator's map.

Studies in Digital Heritage, Vol. 1, No. 2, Publication date: December 2017 

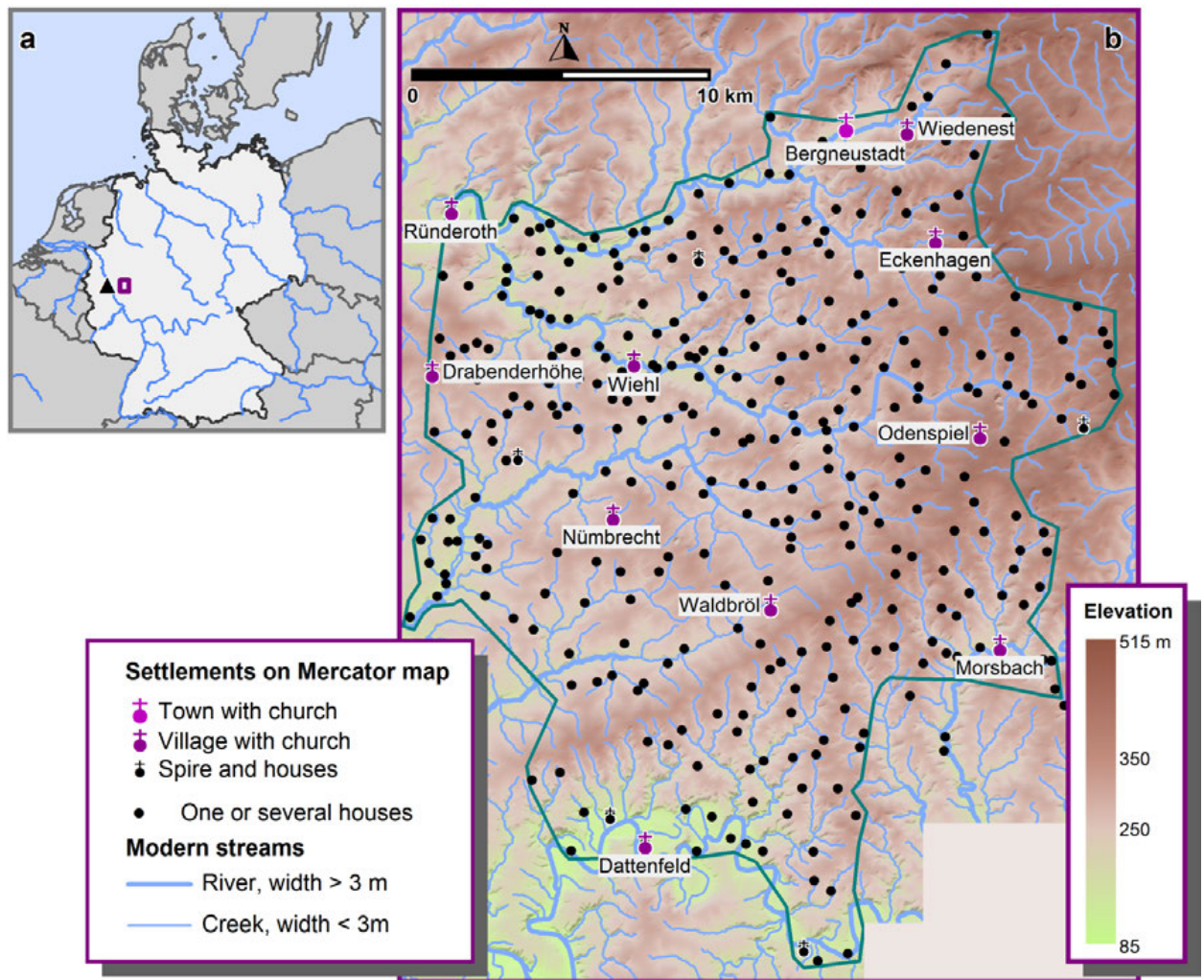

Figure 1. Geographical location of this study: a) area east of Cologne (black triangle) in Germany; b) the study area delimited by a dark green line; settlement locations depicted on the Mercator map are shown (DEM data provided by the ordnance survey institution Geobasis NRW).

Mercator's map shows several long-distance roads. Some of these coincide with boundaries and were therefore probably drawn with extra care. Another road was probably not important for the dispute and its map depiction ends about $5.4 \mathrm{~km}$ east of Wiehl, well within the area covered by the map. If a historical map can be rectified by a simple transformation, transferring the roads to a modern map by digitizing is fairly easy. But the comparison of the true distances and the distances on the historical map presented in the next section demonstrates that a simple transformation is not adequate.

\subsection{Assessing the Accuracy of the Mercator Map}

To assess the accuracy of the Mercator map, an artificial coordinate system was constructed for this map. The artificial coordinates of 348 settlement locations (mostly consisting of several houses only) on the historical map were recorded (Fig. 3c). For each of these locations, the corresponding true coordinate was derived from the mapping of the place names included in the Pampus list referred to above.

A Delaunay triangulation [de Smith et al. 2007, 113-115] of the 348 settlement locations on the modern map was generated. The length of each of the 1029 edges connecting neighboring settlements was 
computed. Very long edges do not allow us to assess the local accuracy; therefore, 42 edges whose length exceeded $3.5 \mathrm{~km}$ were deleted from the edge set to be considered. Moreover, 48 very short edges (length below $0.5 \mathrm{~km}$ ) were omitted because cartographic difficulties are expected when drawing settlements that are very close together. The median length of the remaining edges is $1.28 \mathrm{~km}$. Fig. 2 shows the resulting triangulation edges. Using the artificial coordinate system, the straight-line distances of the lines corresponding to the triangulation edges on Mercator's map were computed. For each edge on the modern map, the length factor is the ratio of the line length on Mercator's map to the corresponding triangulation edge length. If the historical map is not distorted, a constant length factor is to be expected; deviations then indicate settlement locations where the center moved or errors. Fig. 2 shows that the length factor varies in the range of 4.3 to 67.3.

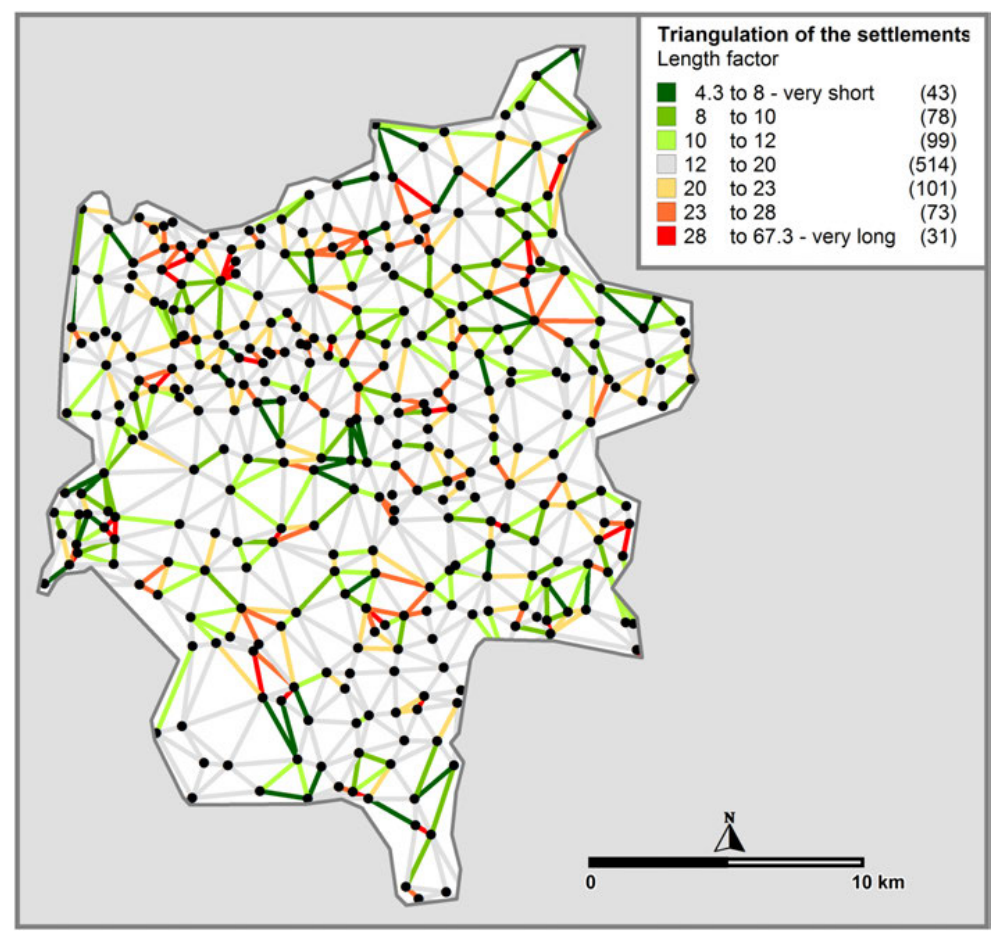

Figure 2. Comparison of the distances between neighboring settlements. The variation of the length factor comparing Mercator and modern map distances is quite high. Moreover, no systematic distortion pattern can be recognized.

The average length factor is 16.2, the median is 15.5. The length factor of 514 out of 939 edges is in the range between 12 and 20. Fig. 2 shows only a very few locations where very short and very long edges meet, indicating that the settlement centers on the historical map and on the modern map do not correspond. In Fig. 2, no pattern can be detected in the spatial distribution of the distortions of Mercator's map.

A more detailed illustration of the map distortion is given when comparing Figs. 3a and 3c. The locations of the place names listed by Pampus [Pampus 1998] are shown in Fig. 3a. Those locations that are recorded on Mercator's map are marked by a white dot in Fig. 3a. In Fig. 3a, the edge 
connecting Waldbröl, the village with a church, and Brenzingen, is dark green, i.e. the distance indicated on Mercator's map is much shorter than the true distance. In contrast, the edge between Büscherhof and Baumen is red because the distance on Mercator's map is much longer than the true distance.
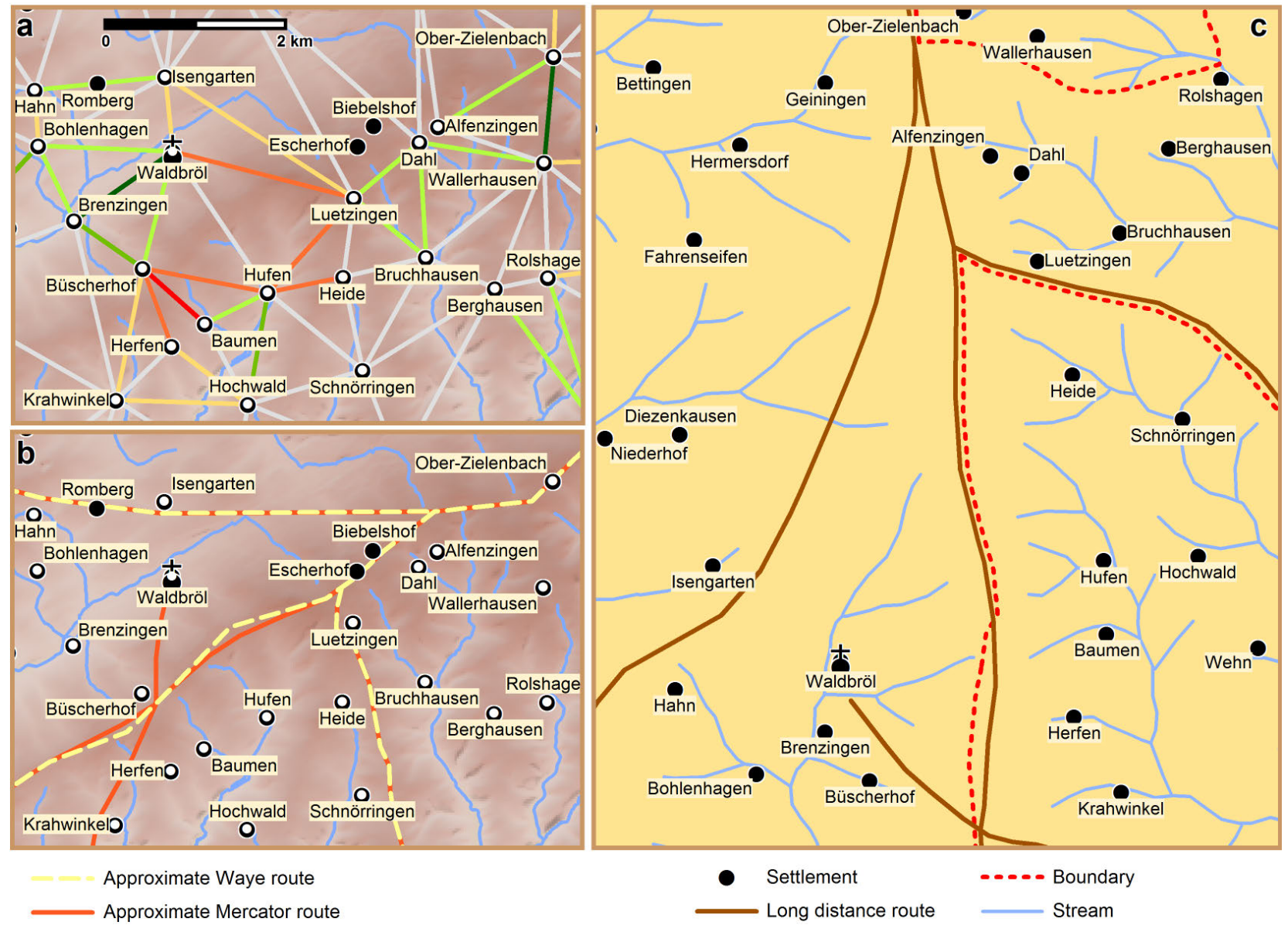

Figure 3. a) Detail: Triangulation of neighboring settlements (see Fig. 2); b) approximate routes reconstructed on the basis of settlement locations and water bodies; c) Digitized topographic features of a Mercator map section roughly corresponding to the modern map sections a and $b$. Unfortunately, the publishing fee for a very small section of this map is quite high, so only the most relevant digitized features are shown. ( $a$ and $b$ are based on the digital elevation model DEM25 provided by Geobasis NRW)

The discussion above shows that rectifying Mercator's map is very difficult. Therefore, the roads were not digitized from the historical map directly. The approximate historical roads were transferred to a modern map, based on place names and water bodies that are depicted both on Mercator's and more recent maps. Fig. $3 \mathrm{~b}$ and $3 \mathrm{c}$ illustrate this approach. The historical map depicts a long-distance route in the area between Isengarten and Waldbröl, but closer to Isengarten, and fairly close to Hahn. 
Unfortunately, Romberg is missing on the Mercator map, therefore it is not possible to decide if the road ran north or south of Romberg.

A reviewer suggested using the QGIS geo-referencer with the thin-plate option to rectify the map. The 348 known settlement locations on the map served as control points. On Mercator's map, each settlement is indicated by a symbol (mostly a red dot) and a small image depicting a few houses and sometimes a church spire or a castle. The control points were placed on the symbol. The result of the QGIS geo-referencer is an uncompressed tif file of nearly $1 \mathrm{~GB}$; the mean error is 9.1 pixels. The rectification was successful in that the symbols indicating settlements on Mercator's map were placed very close to the corresponding control point location on the modern map. But often the small images of houses are severely distorted in the rectified map, and some of the place names are no longer readable. Two black holes, the larger one with a diameter of nearly $2 \mathrm{~km}$, point toward some trouble. The location of small streams in steep areas most probably did not change much over the past 500 years, but for some creeks distances of $400 \mathrm{~m}$ or more can be observed when comparing the rectified and the modern positions. Most sections of the transferred Mercator routes are within a $200 \mathrm{~m}$ buffer of the rectified routes. Large distances are mainly due to the fact that the topography was taken into account when transferring the historical roads to the modern map. For instance, the routes avoid crossing streams. A road on the ridge that is also a drainage divide, midway between Waldbröl and Baumen, was drawn on this ridge. This road is closely related to the historical boundary. On Mercator's map the road is labelled "Die alte holes straiß"; the German word "alte" implies that this road existed a long time before the map was drawn. Another road on Mercator's map was labelled "Die alde Broederstraiß"; this road runs in a west-east direction starting in Drabenderhöhe towards Odenspiel (Fig. 4). So some of the roads analyzed in this study are considerably earlier than 1575.

\subsection{Additional Historical Maps Covering the Study Area}

The dispute concerning the territory boundaries continued after 1575, and this was the reason why the Waye map [Waye and Waye 1607] was created. The original map has disappeared; the copy of the map published in 2004 relies on two copies drawn about 100 years ago. This map is mainly a modified copy of Mercator's map; some of Mercator's road sections are missing, some are added. The approach used for transferring the road sections depicted on Mercator's map to the modern map were also applied for the Waye map (Fig. 4).

The set of maps finished by Ploennies in 1715 [Ploennies 1715] also shows the main long distance roads of that time. These maps are distorted, too; therefore the routes were manually transferred to the modern map as outlined above. Erich Philip Ploennies worked as a cartographer for the rulers of the Berg territory. Unfortunately, part of the study area belonged to another territory at that time. For these areas, Ploennies' maps show only the main settlements and the road depictions are less precise. This is the reason why the west-east connection north of Waldbröl derived from the Ploennies maps appears very straight and deviates from the routes in this area on both the Mercator and the Waye maps. For most other road sections, the transferred Mercator, Waye and Ploennies roads coincide quite well (Fig. 4). 
1:648 I. Herzog

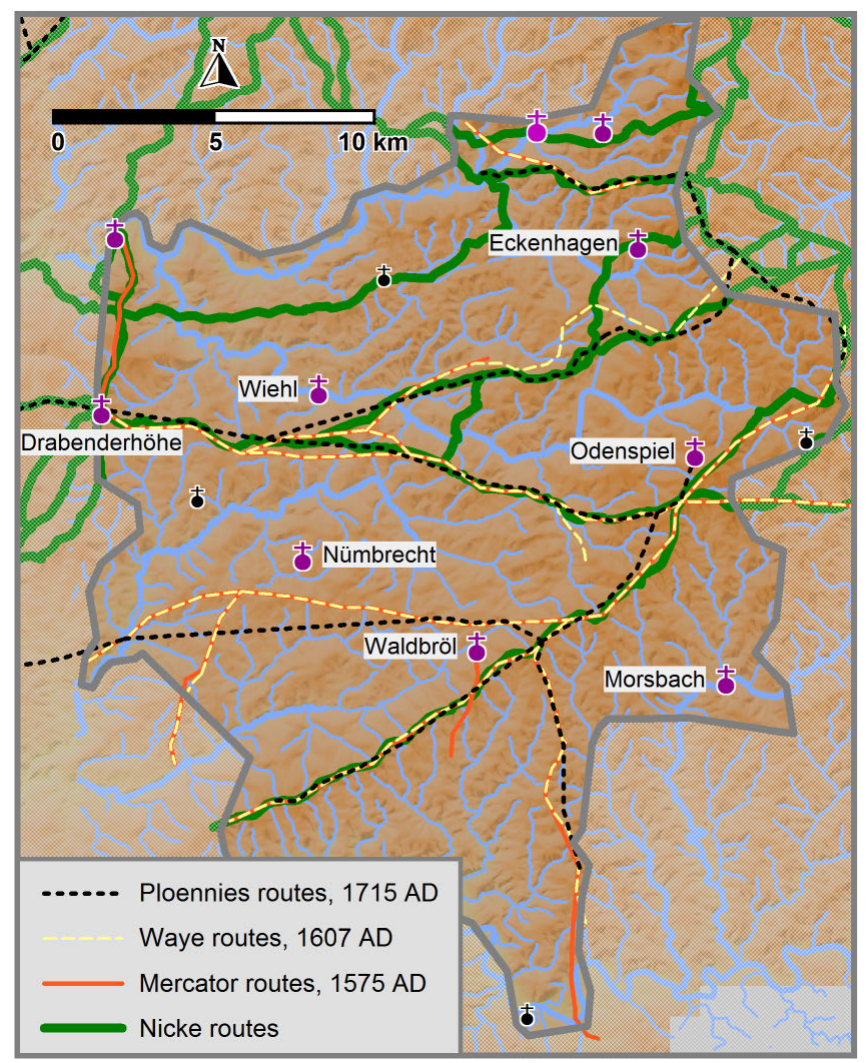

Figure 4. Approximate routes reconstructed on the basis of settlement locations and water bodies (background map: DEM25 provided by Geobasis NRW).

In his book, Nicke [Nicke 2001] describes the long-distance roads in the study area and beyond. The approximate location of the roads based on Nicke's description is also shown in Fig. 4. Nicke knew the historical maps in this area, and so the routes derived from his descriptions differ only slightly from those transferred from these maps.

The first maps of the study area that could be rectified, though with limited accuracy, are attributed to Karl von Müffling. Beginning in 1817, he continued the work of a French group of engineers led by the military geographer Jean Joseph Tranchot after the French occupation of the area west of the Rhine in 1794 [Tranchot and von Müffling 1801-1828].

Karl von Müffling was also the head of a group of Prussian military officers commissioned to create a set of maps covering the Prussian territory [von Müffling 1836-1850] known as Uraufnahme. The subset of these maps relevant for the study area was completed in the years 1840 to 1845. 


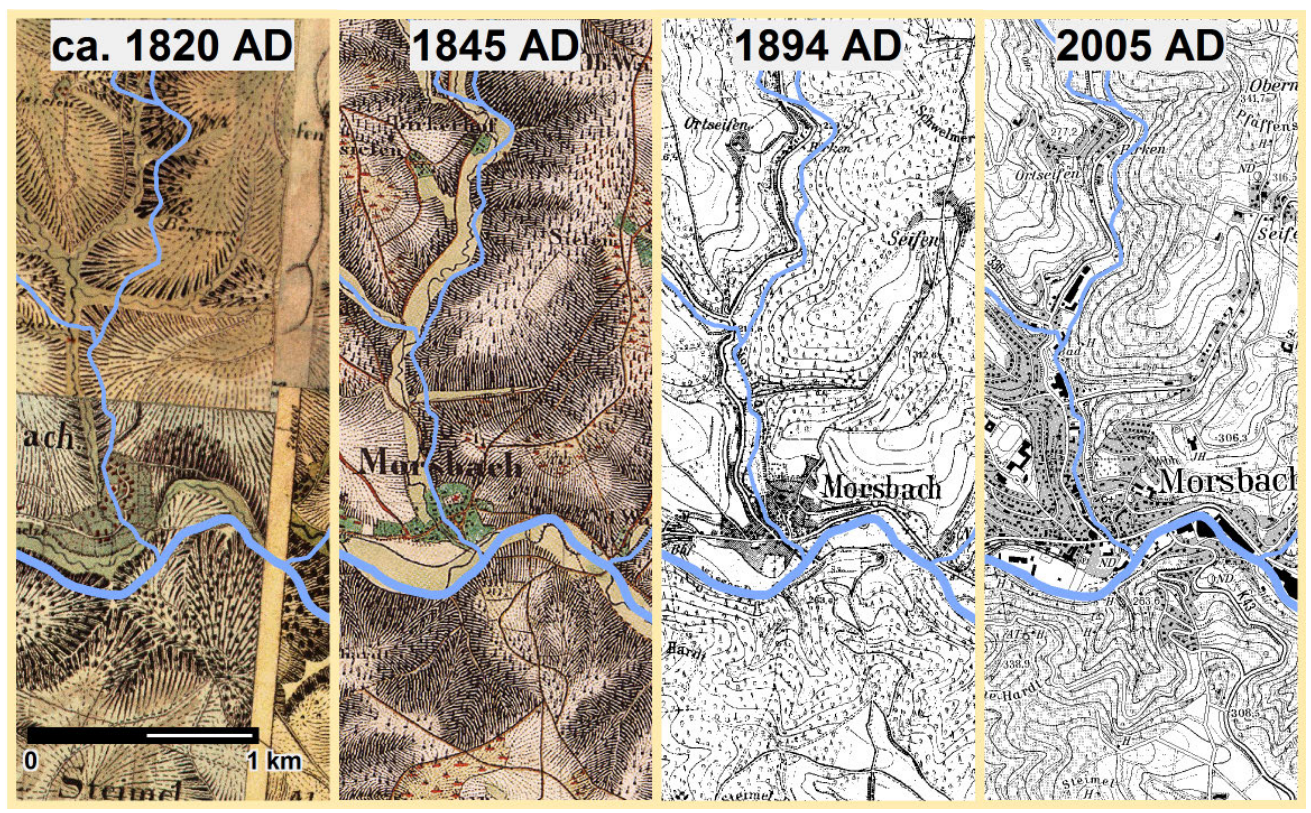

Figure 5. Section of the study area on historical maps and on a modern map, showing also the modern water body layers (WMS provided by Geobasis NRW).

Although the web map service (WMS) provided by Geobasis NRW for the early von Müffling maps is based on an improved rectification of the map sheets, some of the map sheets do not fit well (Fig. 5 leftmost image; Fig. 6). The map section in Fig. 5 suggests not only that the rivers and creeks underwent some regulation but also that position errors of $300 \mathrm{~m}$ might occur. The early von Müffling maps, as well as all later maps on this scale, record many roads and paths, but it is hard to distinguish between main and minor roads. Based on the WMS for the early von Müffling maps, the roads closest to the Mercator roads were digitized (Fig. 6). Gaps in this reconstructed road network are due to the fact that the early von Müffling maps do not cover the total study area; sometimes, no corresponding road was found on the von Müffling maps.

The later von Müffling maps (Uraufnahme) cover the entire study area, and the accuracy was improved, although some problems, especially close to the border of the map sheets, remain. As for the earlier map, Fig. 5 (1845 AD) shows the effects of river and creek regulation as well as the difficulties in distinguishing between main and minor roads. The roads closest to the Mercator roads were also digitized based on the Uraufnahme (Fig. 7).

The map set created between 1891 and 1912 is also known as Neuaufnahme (Fig. 5, 1894 AD). Compared to the previous map sets, the accuracy is improved once again; the borders of adjacent map sheets fit very well. The black and white map image supports readability of the place names. This is why this map set was mainly used for geo-referencing the place names in the list by Pampus [Pampus 1998]. On the modern map (Fig. 5, 2005 AD), the rivers and creeks are regulated, and the small town of Morsbach, which hardly increased in the time between 1820 and 1894, covers a larger area. 


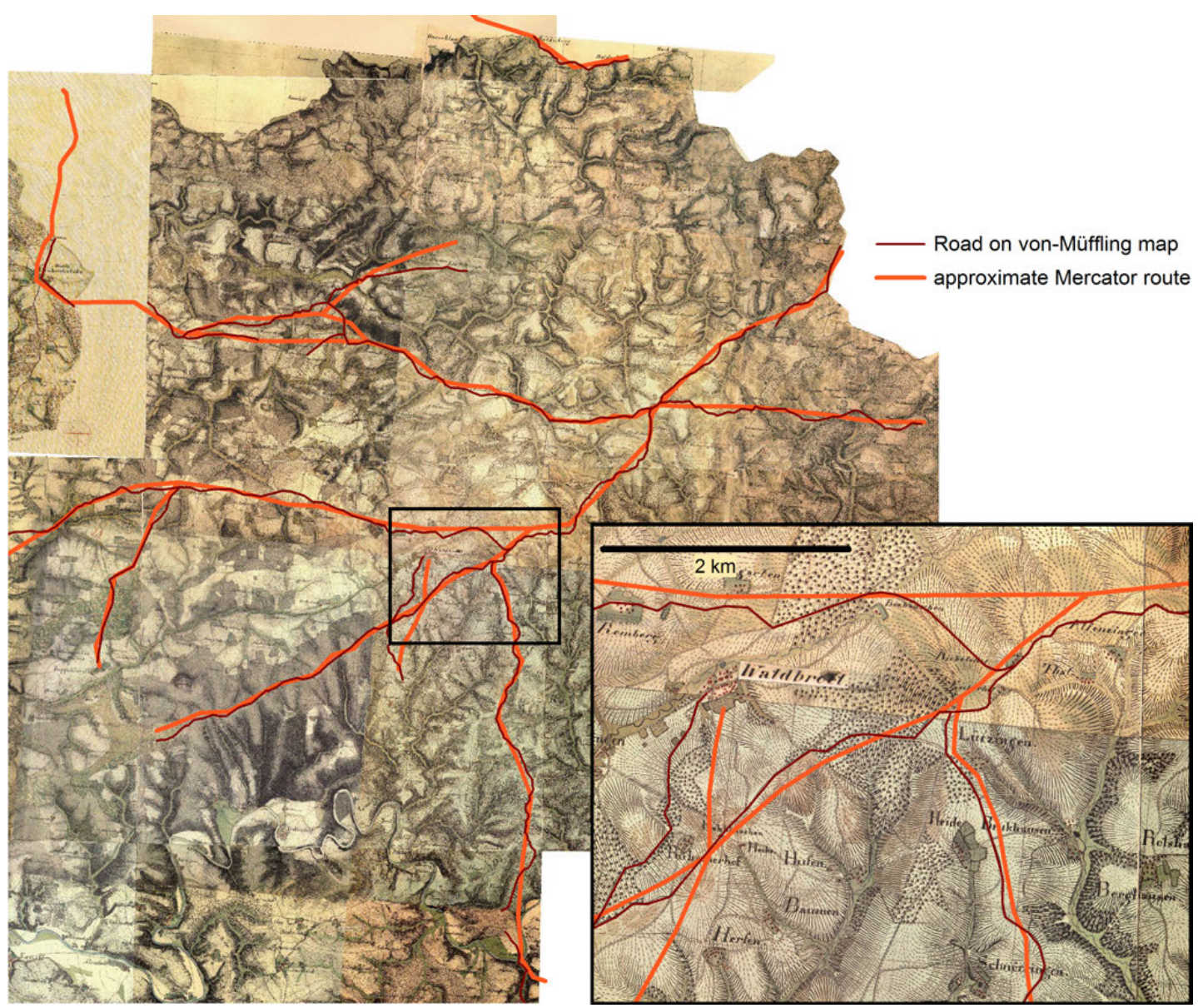

Figure 6. Roads close to the approximate Mercator routes on the rectified early von Müffling maps (WMS provided by Geobasis NRW). The map section marked by a black frame is enlarged.

\section{LEAST-COST ANALYSIS}

The road bundles consisting of the initial transferred Mercator and Waye routes as well as the closest roads digitized from the rectified early and later von Müffling maps provide the ground truth for the LCP calculations. During the last decade, least-cost analysis has become increasingly popular in archaeological research, resulting in quite a few publications. A review of fairly recent case studies can be found in [Herzog 2014].

Table I (left) lists the settlements that are close to the Mercator routes and that are to be connected by LCPs. Eleven pairs of these points, P1 and P2, are to be connected by LCPs for each cost model (Table I, right). The direction of the paths is not considered in this study; it is assumed that the same route is taken on the way from P1 to P2 and back. This requires an isotropic cost function, which is generated by averaging the costs of movement in both directions. Most archaeological LCP studies apply a slope-dependent cost function. For this hilly region, effective slope is computed from the 
digital elevation model (DEM) with a cell size of $25 \mathrm{~m}$ provided by Geobasis NRW. This DEM is based on Lidar data, representing the modern surface with high precision.

Appropriate cost models for reconstructing old trade routes in a region overlapping with the study area were already derived in earlier research [Herzog 2013a]. LCPs avoiding wet soils and with a critical slope of $13 \%$ fitted best to the trade routes. The critical slope is the transition when it becomes more efficient to use switchbacks instead of the direct uphill or downhill route. The critical slope of most vehicles is significantly below that of walkers, mostly in the range of 8 to 16\%. Slope dependent costs were modeled by the symmetric quadratic function discussed by Llobera and Sluckin [Llobera and Sluckin 2007]. For a given critical slope š, the formula for estimating costs of movement on a gradient of slope $s$ is

$$
\operatorname{Cost}(\mathrm{s})=1+(\mathrm{s} / \check{\mathrm{s}})^{2}
$$

where š and s are percent slope values. For the LCPs presented in this study, the critical slope š was set to $12 \%$. Moreover, wet soils were considered as barriers. For raster cells located in wet areas, the slope-dependent costs were multiplied by 5. The multipliers 4 and 6 were tested alternatively.

Table I. Target locations of the LCP calculations

\begin{tabular}{|r|l|c|}
\hline No. & Place name & Year \\
\hline 1 & Waldbröl & 1131 \\
\hline 2 & Reinshagen & 1166 \\
\hline 3 & Ründeroth & 1174 \\
\hline 4 & Oberwiehl & 1316 \\
\hline 5 & Drabenderhöhe & 1353 \\
\hline 6 & Erdingen & 1382 \\
\hline 7 & Oberzielenbach & 1464 \\
\hline 8 & Oberelben & 1484 \\
\hline 9 & Seifen bei Spurkenbach & 1487 \\
\hline 10 & Hardt (Reichshof) & 1509 \\
\hline 11 & Ruppichteroth & 843 \\
\hline 12 & Altenherfen & $?$ \\
\hline 13 & Kohlberg & $?$ \\
\hline 14 & Halsterbach & 1509 \\
\hline 15 & Dümmlinghausen & 1465 \\
\hline 16 & Kalbertal & 1388 \\
\hline & & \\
\hline
\end{tabular}

\begin{tabular}{|c|c|}
\hline $\mathbf{P 1}$ & $\mathbf{P 2}$ \\
\hline 1 & 9 \\
\hline 2 & 7 \\
\hline 11 & 8 \\
\hline 12 & 6 \\
\hline 13 & 7 \\
\hline 6 & 10 \\
\hline 5 & 6 \\
\hline 5 & 4 \\
\hline 4 & 16 \\
\hline 5 & 3 \\
\hline 14 & 15 \\
\hline
\end{tabular}

Numbered list of place names and the year when they were first mentioned in historical sources according to Pampus [Pampus 1998].
List of point pairs (P1, P2) to be connected by LCPs. Numbers in the P1 and P2 columns refer to the numbers in the place name list on the left. 
For possible ford locations identified on the earliest von Müffling maps, a multiplier of 2 was chosen. Buffers for line-shaped water bodies ensure that diagonal barriers cannot be breached. The algorithm applied for LCP calculations allows spreading in 24 directions.

Figure 7 shows the results of the LCP calculations. These simple cost models work surprisingly well: The LCPs are very close to the ground truth route bundle and coincide for most road sections. A wetness multiplier of 6 generates some detours (Fig. 7 left); wetness multipliers of 4 or 5 are more appropriate. Some of the differences between the LCPs and the digitized roads might be caused by modern man-made landscape modifications (e.g. quarries, regulations of rivers and creeks, dam construction for water reservoirs). Including an additional ford location near a bridge on the later von Müffling map probably could have avoided the detour of the LCPs between points 14 and 15 .

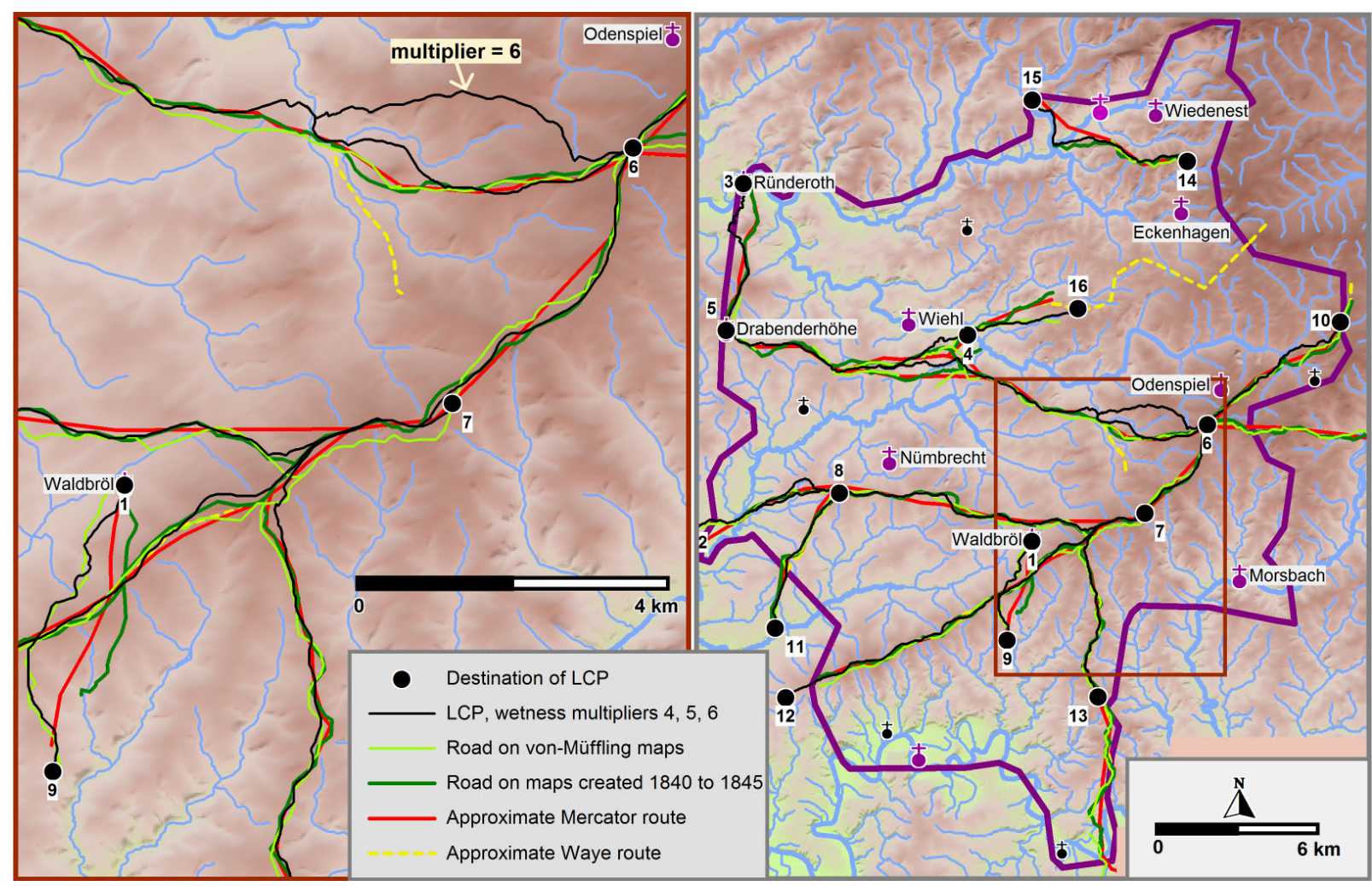

Figure 7. Results of least-cost path calculations: The LCPs are very close to the historical routes. In some sections of the routes, a wetness multiplier of 6 generates LCPS deviating from the historical routes, suggesting that multipliers of 4 or 5 are more appropriate. The map section marked by a brown frame in the map on the right is shown in the left part of the image at a larger scale (background map: DEM25 provided by Geobasis NRW).

South of Wiehl, the bundle of possible routes covers a broader zone than in most other parts of the study area. The LCPs connecting points 5 and 6 are located in the center of the broad zone. The LCPs in the eastern half of this zone are very close to roads depicted on the historical maps created between 1840 and 1845; these roads were not selected when digitizing the closest roads to the 
approximate Mercator routes. For the short road between points 1 and 9, the LCP is closest to the road digitized from the early von Müffling maps. Corresponding roads are also depicted on the later von Müffling maps, but these were not as close to the approximate route as the ones digitized.

The LCP results are supplemented by an accessibility map (Fig. 8). Accessibility can be measured in terms of the size of the site catchment. When considering catchments of different sizes, the inner catchments are generally more important than the bands at a distance. This distance decay can be modeled by a least-cost Kernel Density Estimation (KDE) approach. Technically speaking, the accessibility of each raster cell in the study area is calculated by least-cost KDE for a dense grid of points applying a radial-symmetric Epanechnikov kernel with a radius of $1 \mathrm{~km}$ (for details see [Herzog 2013b]).
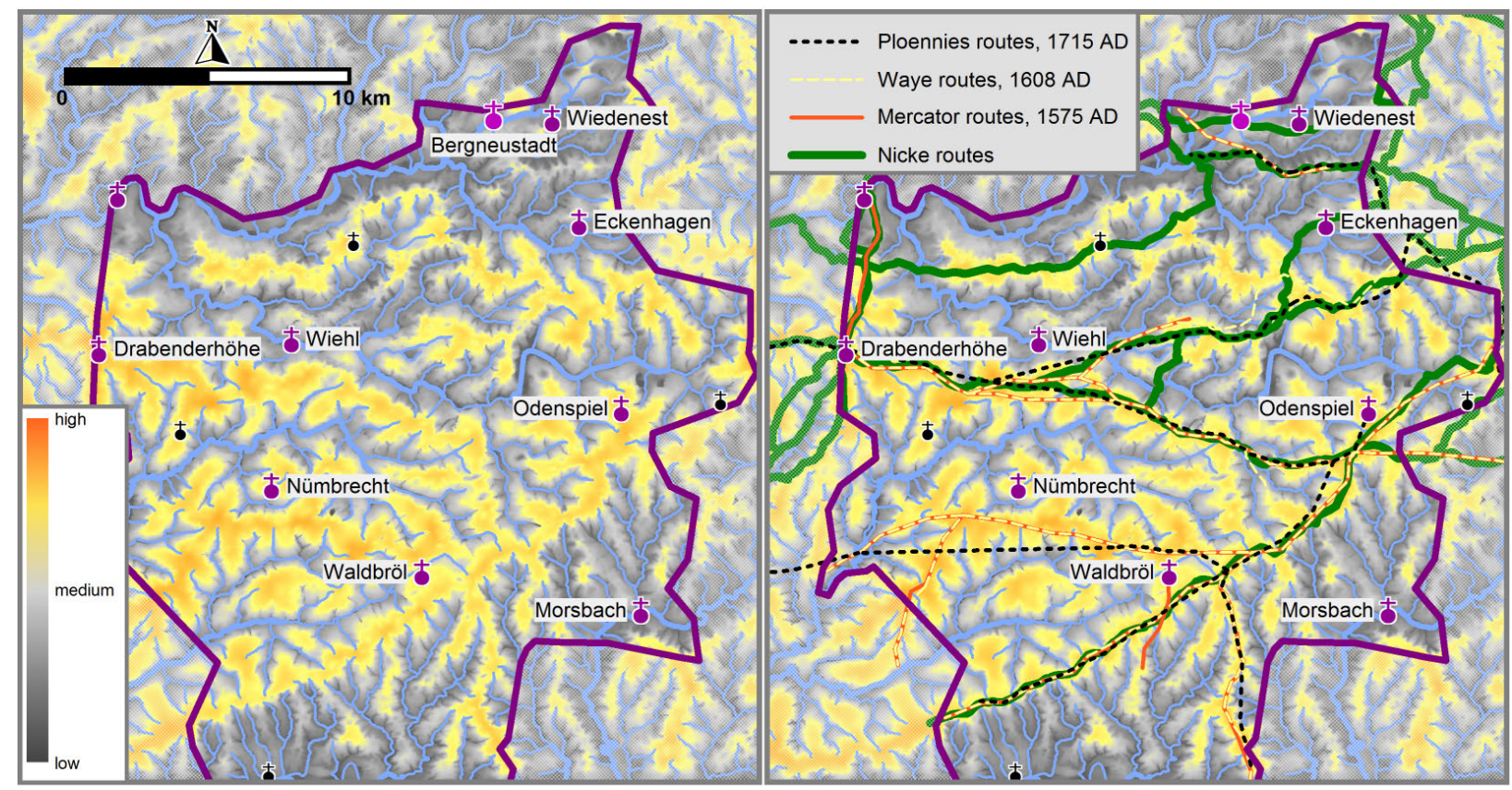

Figure 8. Background: Accessibility map based on least-cost Kernel Density Estimation; the radius of the kernel is $1 \mathrm{~km}$; multiplier 5 for wet areas.

The cost model applied for the least-cost KDE calculations is again the slope-dependent cost function with a critical slope of $12 \%$ combined with a multiplier of 5 for wet areas. A radius of $1 \mathrm{~km}$ was chosen because this radius was suggested by Llobera [Llobera 2000] for calculating accessibility at a middle range.

Fig. 8 shows corridors of high accessibility; these are the ridges in this landscape. The areas surrounding rivers and creeks were assigned low accessibility values. Nearly all routes are located within high accessibility corridors. Within such a broad corridor, small deviations from the least-cost path result in small amounts of extra costs. Therefore, it is plausible to assume that LCPs within narrow corridors of high accessibility reconstruct historical routes with higher reliability. 


\section{DETECTING TRACES OF SUNKEN ROADS USING LIDAR DATA}

The previous sections identified several possible routes for the roads depicted on Mercator's map. For most road sections, the results of the initial method used to transfer the roads on the modern map were not too bad. Probably the true roads can be found within a small buffer zone enclosing the possible routes discussed above. The aim of this section is to analyze Lidar data in the vicinity of these possible routes in order to detect traces of the old roads. Such traces indicate with high probability the correct location of the historical roads. The first step towards this aim is the selection of appropriate methods for detecting sunken roads.

\subsection{Identifying Suitable Methods for Visualization of Sunken Roads in Lidar Data}

Nowadays Lidar data of the study area is readily available. The ordnance survey institution responsible for the part of Germany including the study area provides a WMS with several different relief shading visualizations of the Lidar data (Fig. 9, Ordnance-Survey images). In Fig. 9, the image with the label "Hillshade (NE)" clearly shows the disadvantages of considering only one hill shading direction (in this case: north east).
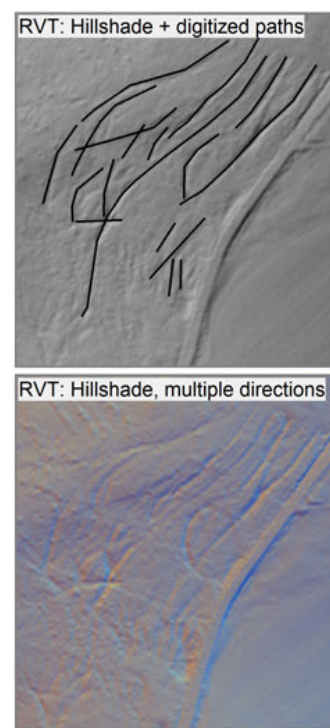

Vertical Mapper: Hillshade
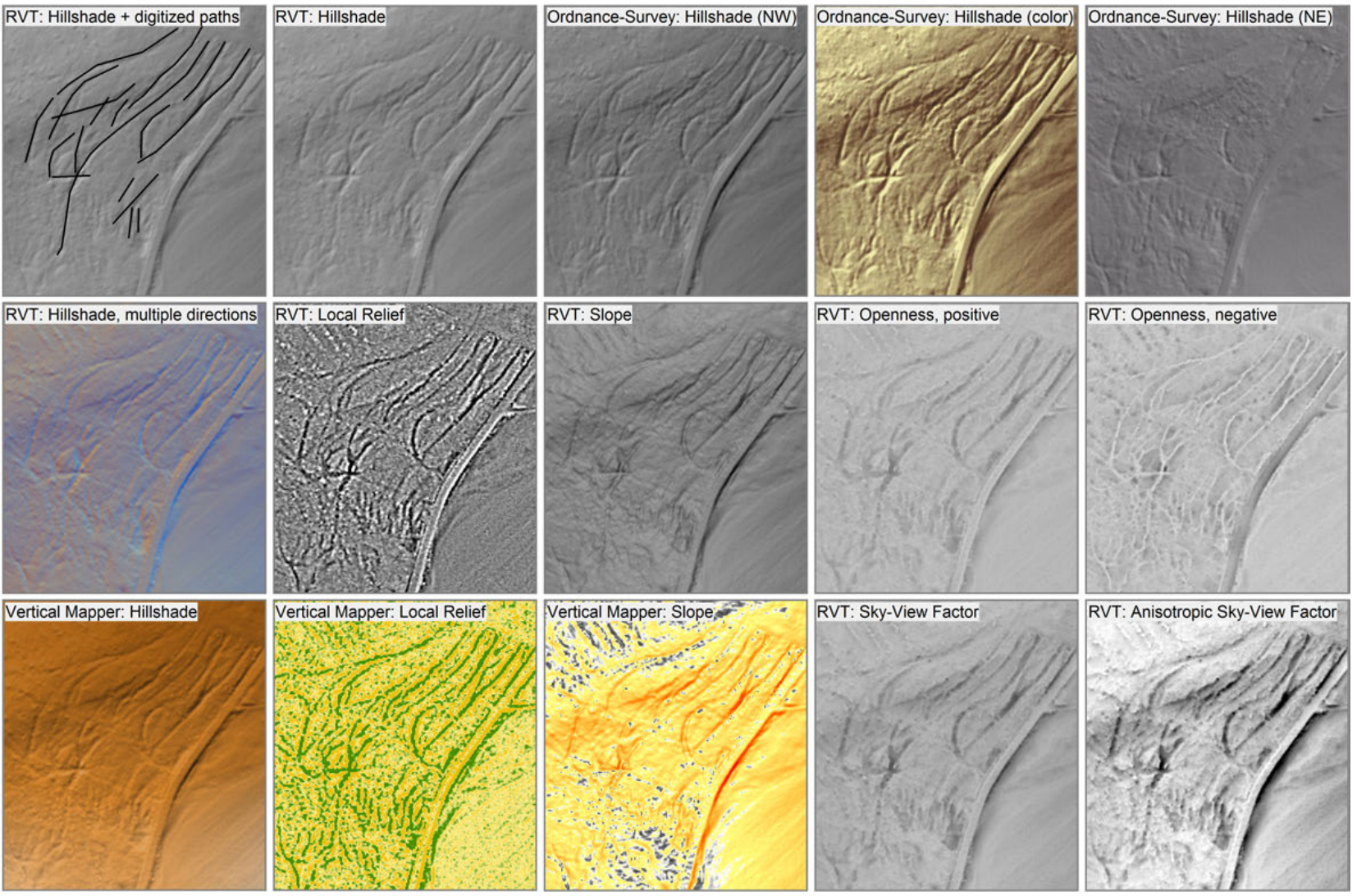

Figure 9. Sunken roads visualized by several methods (based on Lidar data and WMS layers provided by Geobasis NRW). 
Several alternative methods have been published, with the aim of improved visualization of archaeological sites. Some of these methods like slope maps are implemented in most GIS programs. Two software programs are freely available that provide methods developed for archaeological feature detection: LiVT [Hesse 2014] and RVT [Zakšek et al. 2016]. LiVT was written by Ralf Hesse at the State Office for Cultural Heritage in Baden-Württemberg [Hesse 2016]. The software requires a 64 bit Windows operating system; none of the standard Geospatial Data Abstraction Library (GDAL) output formats is supported, so that importing the results to a GIS other than Global Mapper is hardly possible. Due to these limitations, the Rhineland Commission for Archaeological Monuments and Sites in Bonn mainly works with RVT [Kokalj et al. 2011; Zakšek et al. 2011]. Moreover, the GIS software MapInfo with the plugin Vertical Mapper is used, which also supports some of the visualization recommended for Lidar data [Herzog et al. 2016].

The ordnance survey institution Geobasis NRW pre-processed Lidar data resulting in a raster grid with a resolution of $1 \mathrm{~m}$ (DEM1). The Rhineland Commission for Archaeological Monuments and Sites obtained both the DEM1 and the DEM1L consisting of irregularly distributed Lidar points. The DEM1L is also the result of pre-processing; for instance, points on the roofs of buildings are removed so that the point cloud has some gaps. These gaps complicate the interpolation of the DEM1L data, and interpolation with a large search radius is quite time-consuming. In forest areas, hardly any improvements are visible when using higher resolution DEMs based on DEM1L data instead of DEM1 data [Herzog et al. 2016]. For these reasons, all images in Fig. 9 are either based on the WMS layers or on the DEM1 data.

Hesse [Hesse 2016] mainly recommends the methods Accessibility and Sky-View Factor for sunken road visualization, whereas in his view the results of Shaded Relief and Trend Removal or Local Relief Model are only moderately suitable. Unfortunately, the Accessibility method is only supported in his LiVT program. Our tests of different visualization methods suggested that besides the hill-shading approaches, "Local Relief" and "Openness negative" provide the best results in terms of sunken road detection (Fig. 9). But Fig. 9 also shows the difficulties of reliably identifying sunken roads based on Lidar images. Some dendritic structures are visible in the southern part of the map section considered, but are these remains of sunken roads? If a linear depression is rather short, fairly narrow, not very deep or not accompanied by a bundle of other linear depressions, the risk of misinterpretation rises. Sunken roads with a fairly steep gradient may have been modified in width and depth by heavy rains in the past (pers. comm. Renate Gerlach) so that they can be easily confused with the remains of a temporary or small creek not recorded in modern topographic data.

Therefore, validation is required for sunken road candidates detected by visualization of Lidar data. An initial validation can be performed by checking cross sections in the DEM. Yet the features detected on the computer screen are best validated by surveying in the field (or in the forest). So on a nice Sunday in October 2016 a fairly small number of the locations with possible sunken roads were visited and some photographs taken. No obvious misinterpretations were detected.

\subsection{Results of Sunken Road Detection Using Lidar Data Visualizations}

The DEM1 is supplied in ASCII files that contain a list of $\mathrm{x}, \mathrm{y}, \mathrm{z}$ coordinates, each file covering $2 \mathrm{~km} \mathrm{x}$ $2 \mathrm{~km}$. These files were converted to the ESRI ASCII format; files in this format can be processed both 
by RVT and Vertical Mapper. The study area is covered by 141 of these $4 \mathrm{~km}^{2}$ tiles; 83 tiles are intersected by the approximate Mercator routes.

A tool written in the programming language MapBasic assisted the process of identifying and digitizing the sunken road candidates in MapInfo. When clicking on a location, the RVT results available for the corresponding tile are shown, and by another mouse click the desired visualization is loaded.

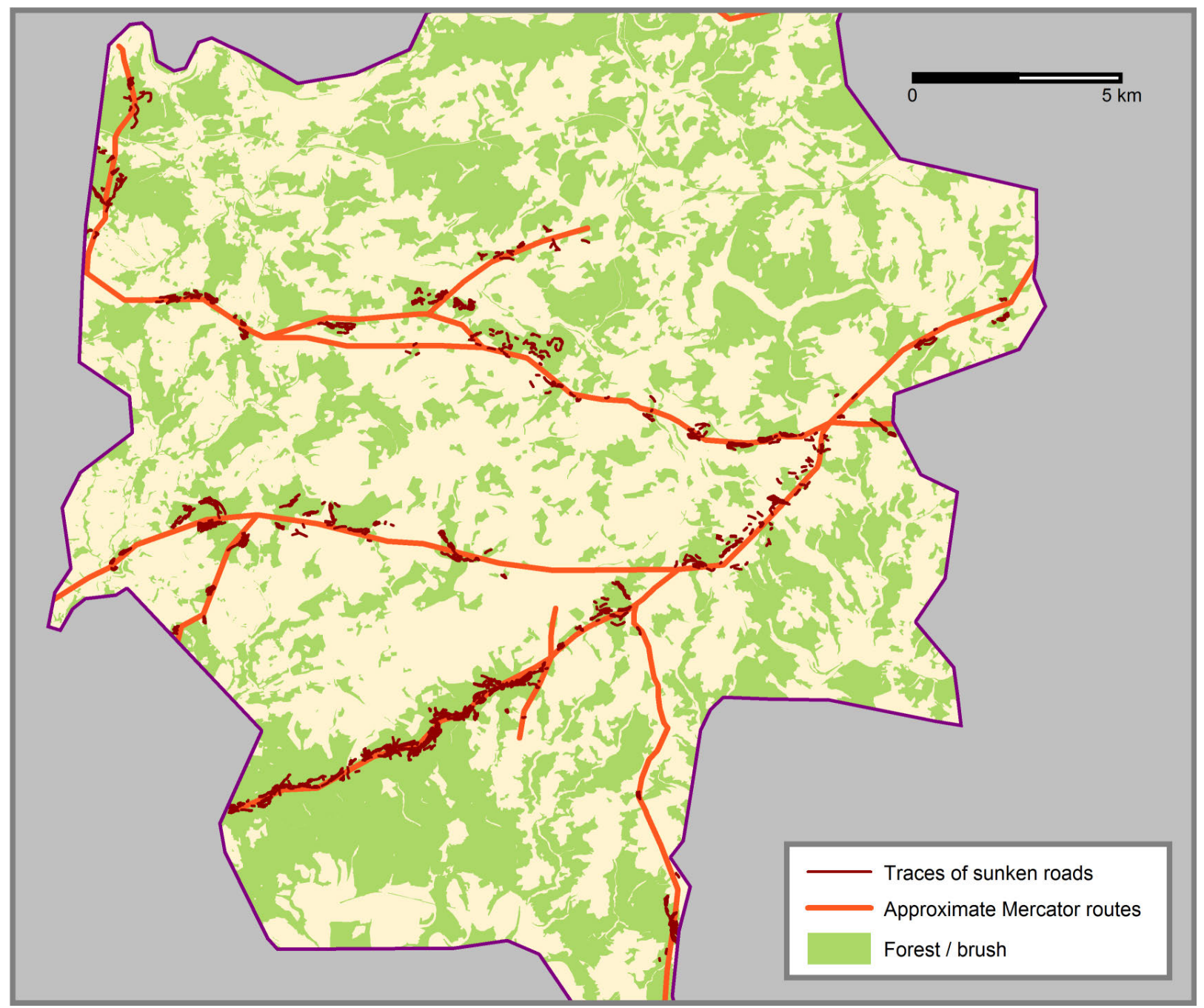

Figure 10. Possible sunken roads in the vicinity of the approximate Mercator routes are mostly visible in forest or brush areas.

Nevertheless, the time required for identifying and digitizing the sunken road candidates on such a large number of tiles with different visualizations available should not be underestimated. Quite a few linear depressions were detected that should be validated by surveying because these features 
do not look exactly like typical sunken roads. Several other interesting non-linear features were discovered as well. In the end, 1514 possible sunken roads with an average length of $93 \mathrm{~m}$ were recorded (Fig. 10). Nearly all of these sunken road remains are located in land used by forest or brush; hardly any of these features are still visible in fields or meadows. Many of these features form typical bundles (Fig. 9), and so the exact location of the historical road cannot be determined. The majority of the sunken roads are fairly well aligned with the approximate Mercator routes. Some are nearly perpendicular to these routes, suggesting minor roads. Some of these minor roads must be very old as well, because on the Mercator map even some of the church villages are not connected to the roads depicted.

\section{DISCUSSION AND FUTURE WORK}

With the Lidar data processing presented above, including validation, many sunken roads associated with the routes depicted on Mercator's map can be identified with high reliability, but this is quite time consuming. A study comparing several work flows for automatic extraction of sunken roads was published in 2014 [Vletter 2014]. Misclassification rates are not given in that study and it seems that the number of cases tested is fairly low. But for validating a procedure for automatic extraction of sunken roads, a large training set of verified sunken roads of different lengths, widths and slopes is required. So the automatic extraction still remains a task for further research.

Fig. 11 shows that nearly all possible sunken roads were identified in areas of high accessibility. But this is mainly due to the fact that the approximate Mercator routes are located in these areas; only the Lidar data close to these routes was inspected. Sunken roads can be detected in many forest areas at some distance from the historical roads considered here. These are most probably the remains of roads connecting the settlements not located close to the main historical roads depicted on the Mercator and the Waye maps. A large number of these off-main-road settlements existed in 1575 (Figs. 1b and 3c). Additional research is needed to determine if the remains of main and minor roads can be distinguished and if typical features allow dating of the sunken roads identified.

The visual inspection of the distribution of the sunken roads recorded creates the impression that the vast majority of these features are part of bundles and that most of the bundles are aligned with the approximately reconstructed roads. Statistical testing of these hypotheses is not straightforward, because the observed sunken road remains are not independent from each other. Therefore, further research should also be directed towards these issues. 


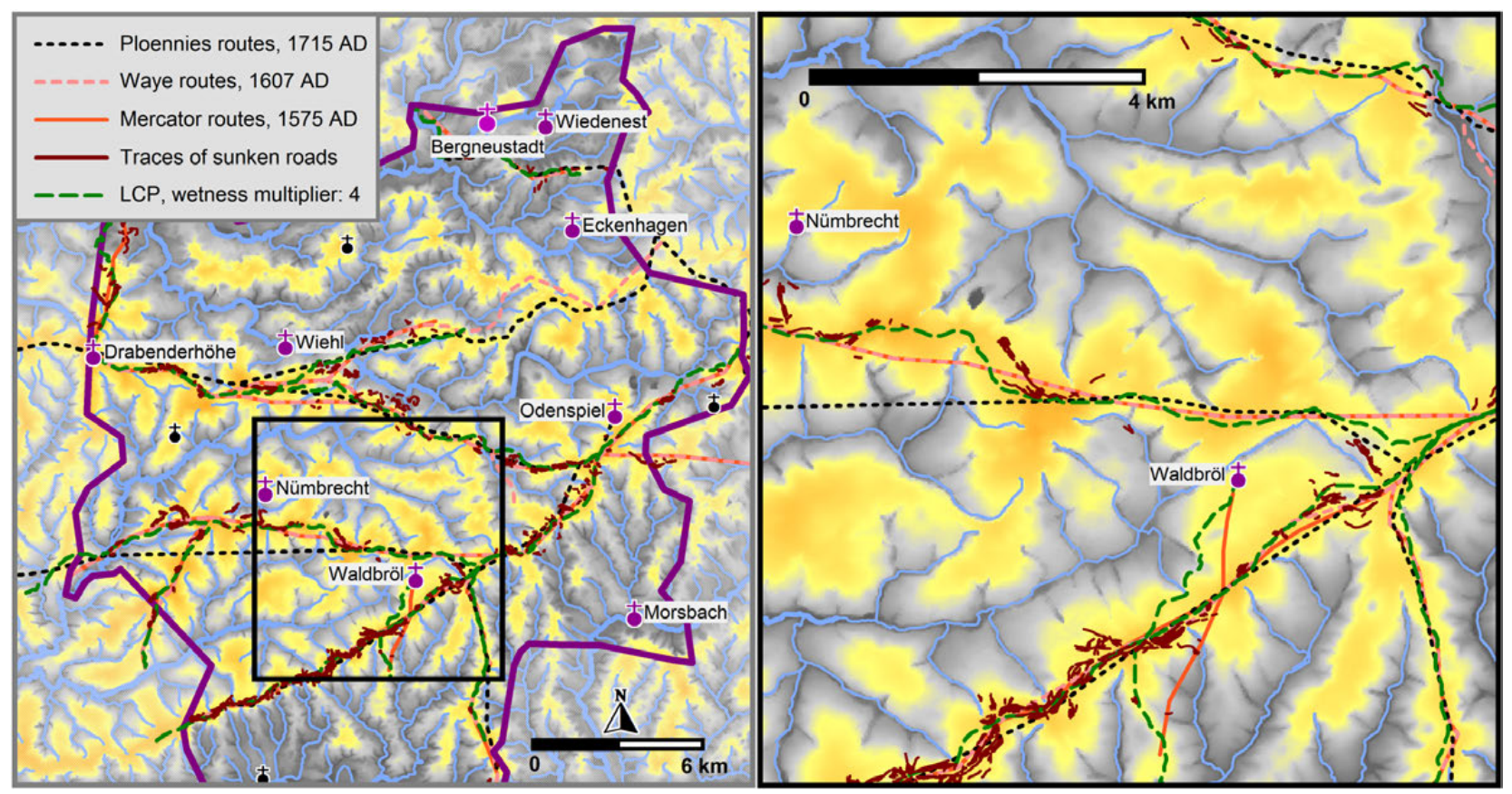

Figure 11. Accessibility map (see Fig. 8) and sunken roads in the vicinity of the approximate Mercator routes. The map section marked by a black frame in the map on the left is shown in the right part of the image at a larger scale.

\section{ACKNOWLEDGEMENTS}

The author would like to thank Sandra Gosteli for scanning the historical maps and Julia Stratbücker for calculating part of the images shown in Fig. 9, as well as nearly all RVT visualizations of Lidar data available at the Rhineland Commission for Archaeological Monuments and Sites. Moreover, the author thanks the reviewers for inspiring suggestions.

\section{REFERENCES}

Irmela Herzog. 2013a. Least-cost networks. In Archaeology in the Digital Era. CAA 2012. Proceedings of the 40th Annual Conference of Computer Applications and Quantitative Methods in Archaeology (CAA), (Southampton 2013), 240-251.

Irmela Herzog. 2013b. Calculating accessibility. In Archaeology in the Digital Era, Volume II. CAA 2012. Proceedings of the 40th Annual Conference of Computer Applications and Quantitative Methods in Archaeology (CAA), Amsterdam, 720-734.

http://dare.uva.nl/cgi/arno/show.cgi?fid=545855

Irmela Herzog. 2014. A review of case studies in archaeological least cost analysis. Archeologia e Calcolatori, 25 (2014), 223-239.

http://www.progettocaere.rm.cnr.it/databasegestione/open_oai_page.asp?id=oai:www.progettoc aere.rm.cnr.it/databasegestione/A_C_oai_Archive.xml:808 
Irmela Herzog. 2015. Analysing settlement patterns in the Bergisches Land, Germany. In Proceedings of the 19th International Conference on Cultural Heritage and New Technologies 2014 (CHNT 19, 2014). Vienna. 15 pages. http://www.chnt.at/proceedings-chnt-19/

Irmela Herzog et al. 2016. Systematische Auswertung von LiDAR-Daten im Rheinland. Archäologie im Rheinland 2015, 25-27.

Ralf Hesse. 2014. LiVT: Lidar Visualisation Toolbox, version 1.0.0.19. (2014). Retrieved July, 2015 from https://sourceforge.net/projects/livt/

Ralf Hesse. 2016. Visualisierung hochauflösender digitaler Geländemodelle mit LiVT. In: U. Lieberwirth \& I. Herzog (eds.), 3D-Anwendungen in der Archäologie. Computeranwendungen und Quantitative Methoden in der Archäologie - Workshop der AG CAA und des Exzellenzclusters Topoi 2013. Berlin Studies of the Ancient World. Edition topoi, 109-128.

Žiga Kokalj et al. 2011. Application of Sky-View Factor for the Visualization of Historic Landscape Features in Lidar-Derived Relief Models. Antiquity 85 (2011), 327, 263-273.

Marcos Llobera and T. J. Sluckin. 2007. Zigzagging: Theoretical insights on climbing strategies. Journal of Theoretical Biology 249 (2007), 206-217.

Marcos Llobera. 2000. Understanding movement: a pilot model towards the sociology of movement. In Beyond the Map. Archaeology and Spatial Technologies, ed. Gary Lock, 65-84. Amsterdam, Berlin, Oxford, Tokyo, Washington DC: IOS Press.

Arnold Mercator. 1575. Grundtliche Beschreibungh vnd Gelegenheit etlicher warer Grenntzen dem Bergischen Ampt Windeck vnd Herschafft Hombergh betreffend. Copied by Hans Weirich in 1995. Published in 1999, along with 2 pages describing the history of the map by Hans Weirich, Lothar Wirths, and Klaus Pampus: Grenzen des Bergischen Amtes Windeck und der Herrschaft Homburg. Bergischer Geschichtsverein, Abt. Oberberg e.V.

Karl von Müffling. 1836-1850. Preußische Kartenaufnahme 1:25.000; Uraufnahme WMS: http://www.wms.nrw.de/geobasis/wms_nw_uraufnahme Information on the maps: http://www.bezregkoeln.nrw.de/brk_internet/geobasis/sonstige/historische_karten/1836/index.html

Herbert Nicke. 2001. Vergessene Wege. Das historische Fernwegenetz zwischen Rhein, Weser, Hellweg und Westerwald, seine Schutzanlagen und Knotenpunkte. Nümbrecht: Martina Galunder Verlag.

Klaus Pampus. 1998. Urkundliche Erstnennungen oberbergischer Orte. Beiträge zur Oberbergischen Geschichte. Sonderband. Gummersbach.

Erich Philip Ploennies. 1715. Topographia Ducatur Montani (1715), ed. B. Dietz. (1988). Bergische Forschungen XX.

Michael J. de Smith et al. 2007. Geospatial Analysis. A Comprehensive Guide to Principles, Techniques and Software Tools. Leicester.

Jean Joseph Tranchot and Karl von Müffling 1801-1828. Kartenaufnahme der Rheinlande 1:25.000. WMS: http://www.wms.nrw.de/geobasis/wms_nw_tranchot Information on the maps: http://www.bezregkoeln.nrw.de/brk_internet/geobasis/sonstige/historische_karten/1801/index.html

Willem F. Vletter. 2014. (Semi) automatic extraction from Airborne Laser Scan data of routes and paths in forested areas. In Second International Conference on Remote Sensing and Geoinformation of the Environment (RSCy2014). August 2014, 11 pages. DOI: 10.1117/12.2069709 
Johann Waye and Jordan Waye. 1607. Eigentliche Description Theil des Bergschen Ambts Windeck samt Anstossende Grentzen. Map reconstructed based on two late 19th/early 20th century copies by Hans Weirich in 1994. Published in 2004, along with 2 pages describing the history of the map by Kurt Hamburger and Hans Weirich: Die Wayekarte von 1607. Ein Kartendokument zum Siegburger Vergleich. Bergischer Geschichtsverein, Abt. Oberberg e.V. NümbrechtElsenroth.

Klemen Zakšek et al. 2011. Sky-View Factor as a Relief Visualization Technique. Remote Sensing 3, (2011), 398-415.

Klemen Zakšek et al.. 2016. RVT: Relief Visualization Toolbox, version 1.2 (64 bit). Retrieved April 20, 2016 from http://iaps.zrc-sazu.si/en/rvt\#v

Received February 2017; revised April 2017; accepted August 2017. 